\title{
Recent Clinical Results of Endoscopic Bariatric Therapies as an Obesity Intervention
}

\author{
Fateh Bazerbachi, Eric J. Vargas Valls and Barham K. Abu Dayyeh \\ Division of Gastroenterology and Hepatology, Mayo Clinic, Rochester, Minnesota, USA
}

Despite advances in lifestyle interventions, anti-obesity medications, and metabolic surgery, the issue of health burden due to obesity continues to evolve. Interest in endoscopic bariatric techniques has increased over the years, as they have been shown to be efficacious, reversible, relatively safe, and cost effective. Further, these techniques offer a therapeutic window for some patients who may otherwise be unable to undergo bariatric surgery. This article aims to review the literature on the safety and efficacy of currently offered endoscopic bariatric techniques, as well as those that are in the pipeline of end-development and regulatory approval.

Clin Endosc 2017;50:42-50

Key Words: Endoscopy; Minimally invasive surgical procedures; Obesity; Bariatric medicine

\section{INTRODUCTION}

Obesity is a global pandemic, afflicting over 690 million individuals, ${ }^{1,2}$ and results in serious comorbidities, such as hypertension, hyperlipidemia, diabetes, obstructive sleep apnea, and non-alcoholic fatty liver disease., ${ }^{3,4}$ More serious outcomes such as cirrhosis may develop in up to $4 \%$ of obese individuals. ${ }^{5}$ While lifestyle interventions and pharmacological therapies can help achieve weight loss, their outcomes are mild and constantly challenged by a strong counter-regulatory physiologic responses, favoring weight recidivism. ${ }^{6}$ The most successful long-term strategy continues to be bariatric and metabolic surgeries, such as sleeve gastrectomy and Rouxen-Y gastric bypass (RYGBP), which enable patients to lose between $50 \%$ and $75 \%$ of excess body weight. ${ }^{7,8}$ However, despite the success of bariatric surgery, only a small proportion of obese patients eventually undergo these invasive interven-

Received: January 5, 2017 Accepted: January 11, 2017

Correspondence: Barham K. Abu Dayyeh

Division of Gastroenterology and Hepatology, Mayo Clinic, 200 First Street SW, Rochester, MN 55905, USA

Tel: +1-507-266-6931, Fax: +1-507-538-5820, E-mail: AbuDayyeh.Barham@mayo.edu

(c) This is an Open Access article distributed under the terms of the Creative Commons Attribution Non-Commercial License (http://creativecommons.org/ licenses/by-nc/3.0) which permits unrestricted non-commercial use, distribution, and reproduction in any medium, provided the original work is properly cited. tions. Therefore, excess body weight continues to account for millions of preventable deaths annually, along with enormous healthcare costs. ${ }^{9}$

Relatively noninvasive endoscopic modalities have evolved to bridge the gap in obesity management by emulating the anatomic and physiologic alterations through which bariatric surgery promotes weight loss. These minimally invasive options offer a therapeutic window for those who are not surgical candidates, or those who desire an alternative treatment modality with possibly fewer complications and reduced cost.

This review focuses on endoscopic bariatric therapies (EBTs) that are either in clinical practice or in advanced stages of development and regulatory approval, by segregating them into gastric or intestinal-targeted.

\section{GASTRIC INTERVENTIONS}

Gastric volume reduction has been an important component of metabolic surgery. By decreasing the amount of area available for caloric intake, sleeve gastrectomy and laparoscopic RYGBP induce weight loss. Additionally, this reduction catalyzes a change in the neuroendocrine milieu that promotes weight loss. ${ }^{10,11}$ As a result, stomach-restrictive EBTs have been developed, representing an innovative and attractive way to 
treat obesity with a favorable safety profile, gastrointestinal (GI) anatomic preservation, as well as reduced cost. These technologies include space-occupying devices that most commonly take the form of temporarily placed prostheses (e.g. balloons), gastric compartmentalization using endoscopic suturing or plication devices, and, lastly, chyme-aspirating devices.

\section{GASTRIC SPACE-OCCUPYING DEVICES}

\section{The Orbera (Formerly BioEnterics) intragastric balloon}

This is a spherical elastic balloon, placed with endoscopic assistance (Fig. 1A). The device is initially placed transorally in a preloaded catheter, without the use of an endoscope. After advancement into the esophagus, an endoscope is used to visualize its proper placement in the stomach. The balloon is filled with approximately $450-700 \mathrm{~mL}$ of normal saline with optional methylene blue to detect spontaneous balloon deflation. After 6 months, the balloon is removed endoscopically. ${ }^{12}$

Prior to its approval for use in the United States (US), the balloon was widely available in many countries, with over
200,000 balloon insertions performed to date. Its safety has been extensively studied, with the majority of side effects limited to accommodative symptoms such as nausea and vomiting. Serious adverse events (SAEs) such as balloon migration and gastric perforation are rare, and have been limited to rates of $1.4 \%$ and $0.1 \%$, respectively. ${ }^{13}$ Perforation was mostly observed in patients with a history of GI surgery, which is now considered a contraindication for balloon placement in the US. Although an early balloon removal rate of $7.5 \%$ has been reported, early use of proton pump inhibitors, antispasmodic drugs, and anti-emetics in the peri- and post-procedural period may allow for a higher rate of balloon conservation.

A meta-analysis of 55 studies that included 6645 Orbera Intragastric Balloon (IGB) implantations demonstrated a pooled estimate of $13.16 \%$ (95\% confidence interval [CI], 12.37-13.95) of total body weight loss (TBWL) at 6 months. ${ }^{13}$ In a pivotal multicenter randomized non-blinded clinical trial conducted in the US, the TBWL for patients who made lifestyle modifications for 6 months, in addition to the Orbera IGB, was $10.2 \% \pm 6.56 \%(n=116)$ compared with $3.3 \% \pm 5 \%(n=99)$ in the control group (subjects who made lifestyle modifications alone). After 6 months of balloon removal (12 months' inter-
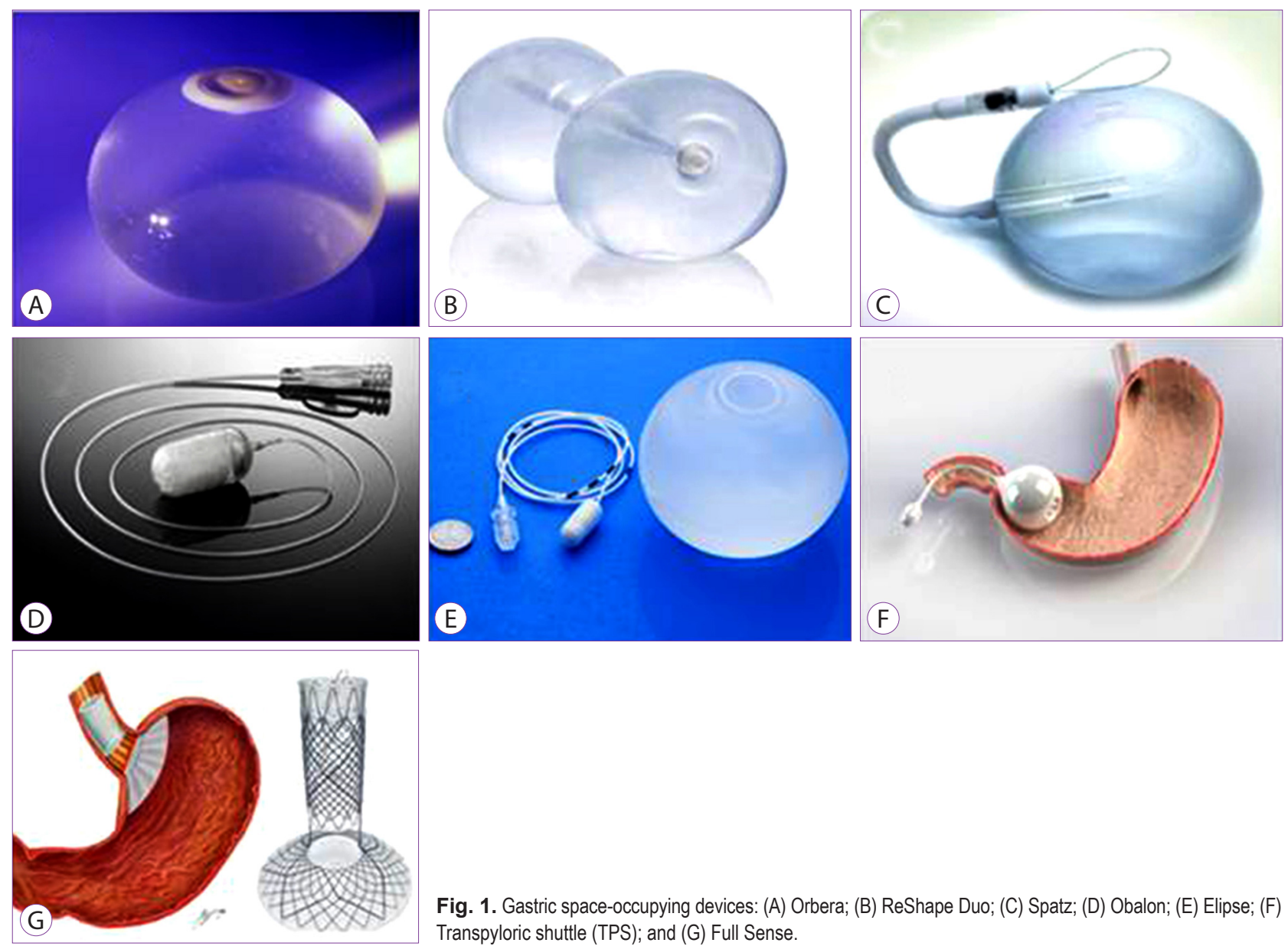

Fig. 1. Gastric space-occupying devices: (A) Orbera; (B) ReShape Duo; (C) Spatz; (D) Obalon; (E) Elipse; (F) Transpyloric shuttle (TPS); and (G) Full Sense. 
val from balloon placement), patients in the prosthesis arm kept off more than $70 \%$ of the weight lost at nadir. The rate of SAEs in the Orbera US pivotal trial was $10 \%$, with the vast majority due to hospital admissions for nausea, vomiting, abdominal pain, or early device removal. Other SAEs included one case of gastric outlet obstruction with diffuse gastritis, one case of gastric perforation with sepsis, one case of aspiration pneumonia, two cases of mucosal esophageal tears (managed endoscopically), and one laryngospasm event. All SAEs resolved without sequelae, and no mortality was observed. ${ }^{14,15}$

Improvements in the course of metabolic syndrome, type 2 diabetes, hypertension, hyperlipidemia, and liver histology of patients with nonalcoholic steatohepatitis (NASH) have also been reported with the Orbera balloon. ${ }^{16-19}$ Successful early ( $\leq 3$ months) weight loss during balloon therapy has been implicated in long-term success, with increased gastric retention and dietary counseling being associated with greater TBWL. ${ }^{20-22}$ Sequential balloon placement has also been studied and has shown promise in patients with super obesity (body mass index $\left.[\mathrm{BMI}] \geq 50 \mathrm{~kg} / \mathrm{m}^{2}\right){ }^{23-26}$ The attractive advantages of the Orbera balloon include its safety profile and global experience with its performance. The balloon was approved for use in the US on August 5, 2015.

\section{The ReShape Duo intragastric balloon}

The ReShape Duo (ReShape Medical, San Clemente, CA, USA) device comprises a dual balloon system that is interconnected by a flexible wire (Fig. 1B). The device is placed and retrieved under endoscopic guidance. Once placed, the balloons are independently filled with $450 \mathrm{cc}$ of normal saline and methylene blue to detect early deflation. Compared to other balloons, the unique dual balloon system affords a minimal risk of prosthesis migration. The device is endoscopically retrieved after 6 months of placement.

In a pivotal multi-center randomized blinded clinical trial conducted in the US, investigators evaluated 187 patients who underwent implantation of the ReShape Duo IGB in addition to lifestyle changes for 6 months and compared them with 139 patients who underwent a sham procedure with lifestyle changes. The authors found that the TBWL at 6 months among patients in the ReShape Duo group ( $n=167)$ was $7.6 \% \pm 5.5 \%$ compared to $3.6 \% \pm 6.3 \%$ in the control group $(n=126)$. Moreover, patients in the ReShape Duo group had a favorable adverse event profile. In the pivotal ReShape trial, early balloon retrieval was necessary in $15 \%$ of the patients, and spontaneous balloon deflation occurred in $6 \%$ of subjects without concomitant balloon migration. Gastric ulcers and erosions were frequent adverse events, initially observed in $39.6 \%$ of the study subjects. However, a subsequent modification in the device design led to a decrease in both ulcer frequency (reduced to $10.3 \%$ ) and ulcer size (1.6 to $0.8 \mathrm{~cm}$ ). Most of the reported ulcers were not clinically significant, except for one ulcer-related upper GI hemorrhage that required blood transfusion. There were no mortality events, balloon migrations, intestinal obstruction episodes, or gastric perforations. Three SAEs were observed with the prosthesis retrieval, including an esophageal mucosal tear, requiring application of hemoclips; a contained cervical esophagus perforation, managed conservatively with antibiotics; and one post-retrieval aspiration pneumonitis. ${ }^{27,28}$

Results from two smaller trials with the ReShape Duo IGB (one randomized non-blinded and another prospective non-controlled trial) have also been reported. ${ }^{29,30}$ The ReShape Duo balloon system was approved by the Food and Drug Administration (FDA) in July 2015.

\section{The Spatz 3}

The Spatz Adjustable balloon System (Spatz Medical, NY, USA) is a silicone-based balloon that is filled with normal saline (400-800 cc). One of its key advantages is the ability to adjust the balloon volume, tailoring it to the tolerance of the patient, and weight loss (Fig. 1C). Outside the US, the Spatz IGB is approved for implantation for up to 12 months. The previous generation of Spatz adjustable balloon enabled considerable weight loss of up to $20 \%$ over 12 months, but had complications related to the design of the device. ${ }^{31,32}$ The Spatz 3 is the most recent generation of the balloon, which overcomes many of the shortcomings of the previous design. It is currently being used in a pivotal multicenter randomized trial in the US to support its regulatory approval in the country.

\section{The Obalon}

The Obalon Gastric Balloon (OGB [Obalon Therapeutics Inc., Carlsbad, CA, USA]) differs from other types of balloons by its gas-filled design (Fig. 1D). It is swallowed in a capsule form, and fluoroscopy is used to verify gastric lodging. The capsule disintegrates once in the stomach, releasing the balloon. The balloon is then filled with $250 \mathrm{cc}$ of air, through a connected catheter, and released from the tether thereafter.

Up to 3 balloons can be swallowed in the same session or sequentially, and balloons are removed endoscopically after 12 to 26 weeks. In a pivotal multi-center randomized blinded clinical trial conducted in the US, 185 patients underwent a combination of lifestyle modifications in addition to the Obalon, while 181 patients underwent lifestyle modifications with a sham placement procedure. The TBWL at 6 months among patients from the Obalon group was $6.9 \% \pm 5 \%$, compared to $3.6 \% \pm 5 \%$ in the control group at 6 months from fist balloon insertion (three balloons inserted at $0,3,9$, or 12 weeks). The balloon seems to be well tolerated, with lower incidence of 
accommodative symptoms compared to those observed with other fluid-filled balloons. The Obalon system was approved by the FDA in September 2016. ${ }^{33,34}$

\section{The Elipse gastric balloon}

The Elipse (Allurion Technologies, Wellesley, MA, USA) is a swallowable self-draining balloon that is naturally expelled through the digestive system (Fig. 1E). The balloon is covered in a biodegradable capsule and is fixed to a slender flexible tube. Once the balloon is swallowed, its placement is confirmed via X-ray or ultrasound and then inflated with 550 cc of fluid. The balloon contains a soluble substance that degrades gradually, allowing the balloon to be excreted naturally though the GI tract. The major perceived advantage of this device is the lack of endoscopic need for placement or removal. In a small proof-of-concept trial, 8 patients with a mean BMI of $31 \mathrm{~kg} / \mathrm{m}^{2}$ received the balloon. The most common adverse events were nausea and vomiting, but no SAEs were reported. All 8 patients lost weight, with a mean weight loss of $2.4 \mathrm{~kg}$ at 6 weeks of therapy. ${ }^{35} \mathrm{~A}$ recent prospective, open label, observational study across multiple centers with 34 patients (mean BMI $34.8 \mathrm{~kg} / \mathrm{m}^{2}$ ) reported $10 \%$ TBWL at 4 months. One patient required endoscopy to confirm balloon placement after it detached in the lower esophageal sphincter, and two patients requested endoscopic deflation owing to intolerance. All balloons were safely expelled (88\% through stool and $12 \%$ through emesis). Over $85 \%$ patients experienced adverse events, with $53.6 \%$ and $64.3 \%$ of patients mainly reporting nausea and vomiting, respectively. ${ }^{35} \mathrm{~A}$ pivotal randomized multicenter trial to support regulatory approval is currently being planned in the US.

\section{The TransPyloric Shuttle}

The TransPyloric Shuttle (TPS [BAROnova, Goleta, CA, USA]) is another type of gastric-occupying device (Fig. 1F). The device comprises a greater spherical silicone orb that is attached to a lesser cylindrical silicone bulb by a flexible cord. Through physiologic peristalsis, the lesser cylindrical component is placed across the duodenal bulb, while the greater orb remains behind the pylorus. The delivery system for the device is advanced through an overtube into the stomach, where the device is deployed and it self-assembles. The base of the greater orb is compliant, allowing it to engage the pylorus, thereby creating an intermittent seal intended to delay gastric emptying, and induce early and prolonged satiety. In the first feasibility study, 20 patients with a BMI of $36 \mathrm{~kg} / \mathrm{m}^{2}$ were randomized to TPS placement for either 3 or 6 months. Patients who had the device for 3 months lost $25.1 \%$ of excess weight while those with the device for 6 months lost an average of $41 \%$ of excess weight. ${ }^{36} \mathrm{~A}$ pivotal multicenter randomized trial is currently underway in the US to support the regulatory approval of this device.

\section{The Full Sense Device}

The Full Sense Bariatric Device (Baker, Foote, Kemmeter, Walburn [BFKW] LLC, Grand Rapids, MI, USA) is another reversible weight loss device that is placed and that is removed endoscopically (Fig. 1G). It comprises an esophageal stent connected to a gastric disk via a strut. By residing in the cardia, it induces satiety and feelings of fullness. Reportedly, unpublished human data with 3 subjects showed $28 \%$ excess weight loss (EWL) in 46 days. A median of $80 \%$ EWL has been reported during a 6-month trial in an unknown number of subjects. These results are reportedly backed by a randomized trial and follow-up crossover trial design, ${ }^{37}$ however, no peer-reviewed data have been published to date.

\section{ENDOSCOPIC SUTURING OR PLICATION DEVICES}

Three gastric remodeling procedures are currently applied in clinical practice worldwide (Fig. 2). These include endoscopic sleeve gastroplasty (ESG), the Primary Obesity Surgery Endolumenal (POSE), and the transoral anterior-to-posterior greater curvature plication with the Endomina ${ }^{\circledR}$ suturing device.

\section{Endoscopic sleeve gastroplasty}

ESG is a transoral endoscopic gastric volume reduction technique that reduces gastric capacity by creating an endoscopic sleeve. ${ }^{38-45}$ This is accomplished by a series of endoscopically placed full-thickness sutures through the gastric wall, extending from the prepyloric antrum to the gastroesophageal junction. This technique reduces the entire stomach along the greater curvature, creating a sleeve. ESG is created using a commercially available endoscopic suturing device (Overstitch;

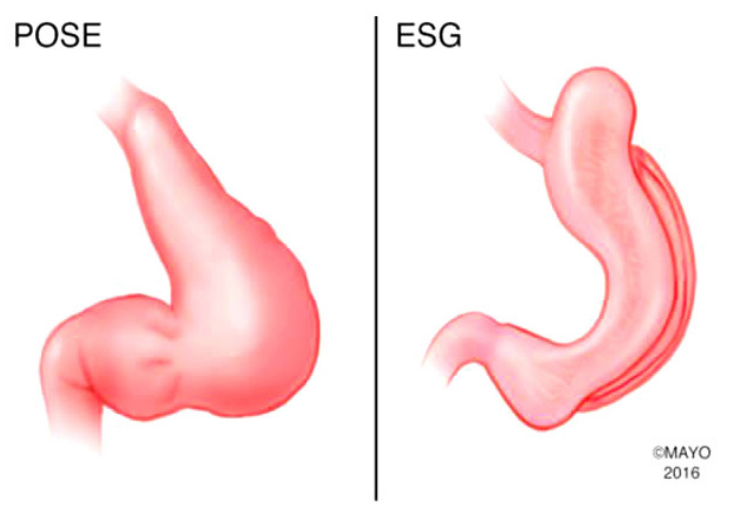

Fig. 2. Endoscopic gastric remodeling techniques. 
Apollo Endosurgery, Austin, TX, USA), which requires a double-channel therapeutic gastroscope to operate. Full-thickness suture placement is aided by the use of a tissue helix device that captures the targeted suture placement site on the gastric wall and retracts it into the suturing arm of the device.

The Mayo Clinic first demonstrated the clinical feasibility of this technique in $2013{ }^{38}$ Since then, multiple groups have demonstrated the safety and efficacy of this technique, reporting 18\% TBWL at 12 months, with an excellent safety profile. In a multicenter study enrolling 242 patients at 3 centers, ESG was associated with $16.8 \% \pm 6.4 \%(n=137), 18.2 \% \pm 11.6 \%(n=53)$, and $19.8 \% \pm 11.6 \%(n=30)$ TBWL at 6,12 , and 18 months, respectively. Five (2\%) adverse events occurred: two cases of perigastric inflammatory fluid collection (adjacent to the fundus) that resolved with percutaneous drainage and antibiotics, one case of self-limited hemorrhage from splenic laceration, one case of pulmonary embolism 72 hours after the procedure, and one case with both a pneumoperitoneum and pneumothorax requiring chest tube placement. All five patients recovered fully, with no further need for surgery. ${ }^{44}$ Further, our Mayo group studied the physiological perturbations that occur after ESG, and it demonstrated significant decrease in gastric emptying, increased satiation, and overall metabolic effects that are potentially crucial to subduing the metabolic dysregulation hallmarks of obesity. ${ }^{39}$

\section{The primary obesity surgery endolumenal}

POSE is performed via a peroral incisionless operating platform (USGI Medical, San Clemente, CA, USA) to place transmural tissue anchor plications that reduce accommodation of the gastric fundus. Three additional plications are placed in the distal gastric body to delay gastric emptying.
The procedure is performed using a large, overtube-style platform that has four working channels that accommodate a slim endoscope and three specialized instruments: the g-Prox EZ Endoscopic Grasper (USGI Medical), a flexible shaft with a jawed gripper for creating and approximating full-thickness (serosa-to-serosa) tissue folds; the g-Lix Tissue Grasper (USGI Medical), a flexible probe with a distal helical tip designed to assist the g-Prox in capturing the target tissue for a full-thickness mini-plication; and the g-Cath EZ Suture Anchor Delivery Catheter (USGI Medical), a catheter system with a needle at its distal tip that, after advancement through the lumen of the g-Prox, penetrates the mobilized target tissue and installs a pair of preloaded paired tissue anchors, joined by suture material holding the plication until there is serosal fusion. To date, there have been two open-label prospective single-arm trials and two randomized controlled trials assessing the safety and efficacy of the POSE procedure. ${ }^{45-49}$ In a pivotal multi-center randomized blinded trial conducted in the US, 221 patients received the POSE in addition to low-intensity lifestyle interventions for 12 months. These patients achieved a $4.94 \% \pm 7 \%$ TBWL compared to $1.38 \% \pm 5.6 \%$ TBWL achieved by the 111 patients in the control group (lifestyle interventions alone). The 34 patients who participated in the lead-in open-label portion of the study achieved $7 \% \pm 7.4 \%$ TBWL at 12 months. The rate of SAEs was $4.7 \%$ ([1.9\% vomiting, $1.6 \%$ nausea, and $0.4 \%$ pain, all requiring longer hospitalization] as well as $0.4 \%$ extragastric bleeding requiring open surgery, and $0.4 \%$ liver abscess requiring percutaneous drainage). ${ }^{48,49}$ Lastly, POSE was associated with improved satiation and gut neuroendocrine reaction. ${ }^{47}$

\section{Endomina system}

This system creates transoral anterior-to-posterior greater
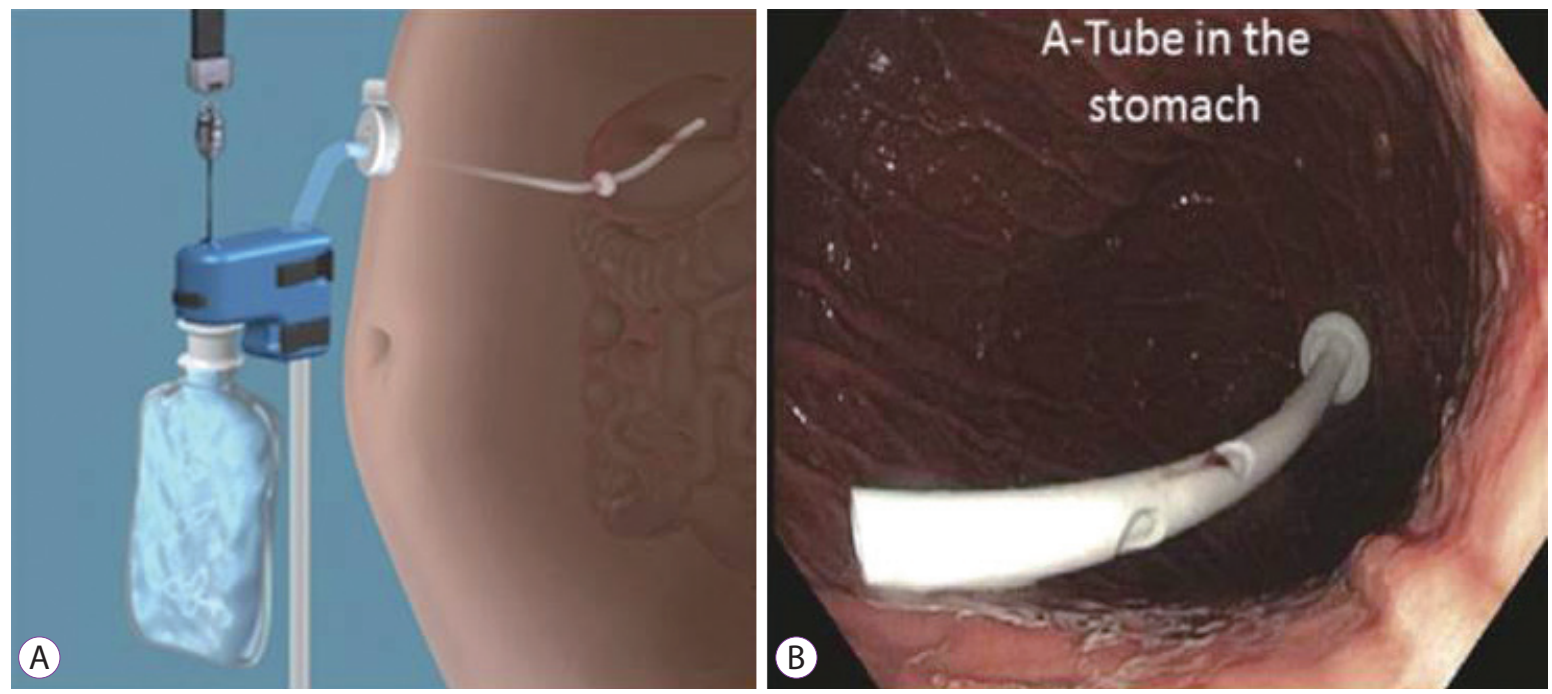

Fig. 3. (A) Aspiration therapy (AT) device; (B) Aspiration tube (A-tube) in the stomach. 

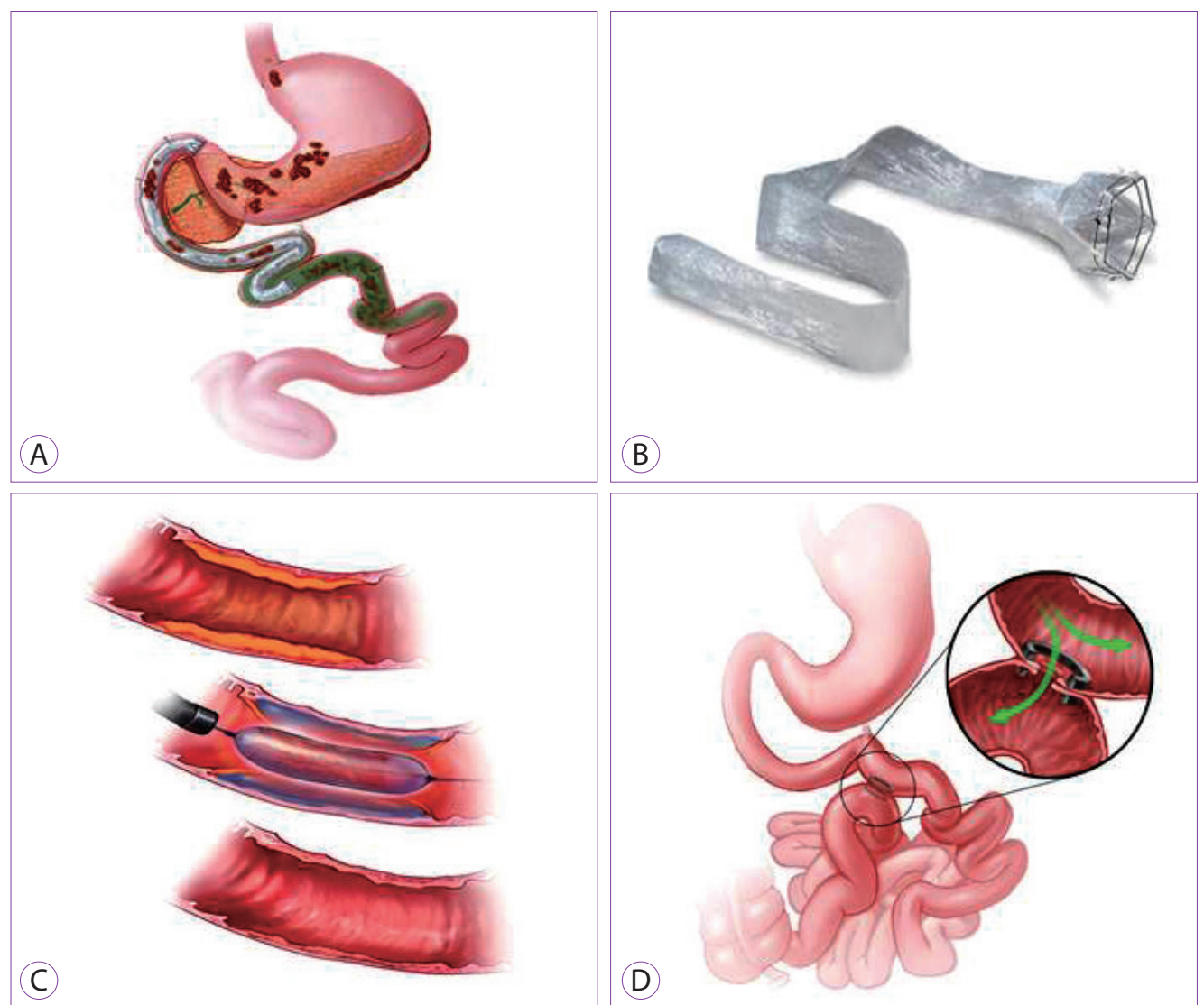

Fig. 4. Small bowel endoscopic bariatric therapies (EBTs): (A, B) Endobarrier device; (C) Duodenal mucosal resurfacing; and (D) Self-assembling magnets for endoscopy.

curvature plications to reduce gastric volume, using an overthe-scope triangulation platform capable of delivering a single interrupted suture anchored by two T-tags (Endomina, EndoTool SA [STT], Gosselies, Belgium).

Huberty et al. reported 6-month weight loss outcomes in 10 patients who underwent this procedure, who showed $11 \% \pm 8 \%$ TBWL with no major adverse events. ${ }^{50}$ The median procedure time was 125 (range, 75-200) minutes, which could have reflected the early learning curve of the technique. Although the results are encouraging and in par with those of other gastric remodeling techniques, final data on the safety of this device as well as long-term efficacy are still unavailable.

\section{ASPIRATION THERAPY}

Aspiration therapy (AT) is a treatment approach for obesity that allows obese patients to dispose a portion of their ingested meal via a specially designed percutaneous gastrostomy tube, known as the Aspiration tube (A-tube) (Fig. 3A, B). The tube is made of silicone and is inserted in a manner similar to that in which standard percutaneous endoscopic gastrostomy tubes are inserted. Two weeks after insertion, the external portion of the tube is shortened and a skin port incorporating a valve is attached flush with the skin. An Aspire Assist device (Aspire Bariatrics, King of Prussia, PA, USA) is connected to the skin port to perform aspiration. An attached water reservoir flushes boluses of tap water into the stomach to facilitate subsequent aspiration cycles. Aspiration is performed via a siphon effect, ideally 20 minutes after consumption of the meal, and typically, a third of the meal is removed and discarded. The process takes only about 10-15 minutes to complete. In a pivotal multi-center randomized open-label clinical trial conducted in the US, 111 patients were enrolled to undergo AT in addition to a lifestyle intervention for 12 months. ${ }^{51}$ Patients who completed the treatment duration $(n=82)$ and showed a TBWL of $14.2 \% \pm 9.8 \%$ were compared with 60 patients receiving lifestyle intervention alone; 31 of them completed the 12-month intervention, with a total TBWL of $4.9 \% \pm 7 \%$. Adverse events included stoma granulation, tissue formation (40.5\%), stoma infection (14.4\%), peritonitis (0.9\%), and gastric ulcer $(0.9 \%)$. The rate of spontaneous fistula closure after removal of the A-tube is yet to be elucidated. ${ }^{51}$ 


\section{SMALL BOWEL INTERVENTIONS}

The duodenum is a critical organ in nutrient trafficking. The success of bariatric surgery has demonstrated the drastic significance of the duodenum and jejunum in terms of glycemic control, and, therefore, the pathogenesis of type 2 diabetes. ${ }^{52}$ Considering the altered neuroendocrine milieu because of bariatric surgery, innovative EBTs were designed to simulate the state of intestinal bypass, with hopes of invoking similar success in weight loss and diabetes resolution (Fig. 4).

\section{EndoBarrier}

The EndoBarrier (Endobarrier GI Dynamics, Lexington, MA, USA) is a $65-\mathrm{cm}$ long Teflon-coated duodenal jejunal bypass sleeve (DJBS) that allows undigested food to reach the jejunum, where it mixes with pancreaticobiliary juices (Fig. $4 \mathrm{~A}, \mathrm{~B})$. The device is anchored to the duodenal bulb through a nitinol crown with barbs. The device (sleeve and anchor) comes in a capsule that is placed under general anesthesia with fluoroscopic guidance. Once the capsule reaches the duodenal bulb, the sleeve is advanced $65 \mathrm{~cm}$ into the small bowel. The anchor is then deployed $5 \mathrm{~cm}$ distal to the pylorus. In order to remove the device, a foreign body hood is used at the end of the endoscope after grasping a custom drawstring, to avoid damage to the GI tract during removal.

A recent meta-analysis of the published literature on this device showed that at 12 months, patients achieved 35.3\% (95\% CI, 24.6\%-46.1\%) EWL. ${ }^{13}$ Four randomized controlled trials compared 12 to 24 weeks of treatment with the EndoBarrier DJBS (90 subjects) with a sham or control arm (84 subjects). The mean \% EWL compared with the control group was significant at 9.4\% (95\% CI, 8.26\%-10.65\%). The DJBS demonstrated an impact on diabetic control after implantation, with improvements in HgbAlc from -0.7 (95\% CI, -1.76 to 0.2; $p=0.16)$ at 12 weeks to $-1.7(95 \% \mathrm{CI},-2.5$ to $-0.86 ; p<0.001)$ at 24 weeks, and -1.5 ( $95 \%$ CI, -2.2 to $-0.78 ; p<0.001$ ) beyond 52 weeks from implantation. This improvement in HgbAlc was statistically significant compared with the sham or control diabetic group, where the EndoBarrier DJBS resulted in an additional $-1 \%$ (95\% CI, -1.67 to -0.4$)(p=0.001)$ amelioration in HgbAlc compared with that observed in controls. A pivotal multicenter double-blinded sham control trial in the US was terminated early after enrolment of 325/500 patients owing to a $3.5 \%$ incidence of hepatic abscess formation. With twothird enrollment, compared to the sham group, subjects who received the DJBS lost significantly more weight at 12 months (TBWL $7.7 \% \pm 9.6 \%$ vs. $2.1 \% \pm 5.4 \%, p<0.0001$ ) and had more significant improvement in HgbAlc ( $-1.1 \pm 1.5$ vs. $-0.3 \pm 1.6)$. Early device retrieval owing to adverse events was performed in $10.9 \%$ of patients. ${ }^{53}$ Second-generation DJBSs with atrau- matic anchoring and retrieval systems are currently undergoing human clinical trials.

\section{Other small-bowel EBTs}

Small-bowel EBTs that are in earlier stages of development include gastroduodenojejunal bypass sleeve (ValenTx, Inc., Hopkins, MN, USA), duodenal mucosal resurfacing procedure (Fractyl Laboratories, Cambridge, MA, USA) (Fig. 4C), and self-assembling magnets for endoscopy (Fig. 4D) (GI Windows, Boston, MA). In the duodenal mucosal resurfacing procedure, thermal ablation of the superficial duodenal mucosa is achieved with the aid of a special catheter that delivers hot water after a sub-mucosal lift. Mucosal remodeling may hypothetically reset the diseased duodenal enteroendocrine cells, thus restoring signaling, which can improve diabetes control through an incretin effect, with minimal transient decrease in body weight. ${ }^{54}$ With the self-assembling magnets, a dual-path enteral bypass is created between the proximal jejunum and ileum, thus, partially diverting bile and nutrients to the terminal ileum, and potentially activating bile signaling pathways, as well as enhancing incretin secretion, resulting in improvement in diabetes, and weight loss.

\section{CONCLUSION}

Obesity continues to be pervasive in our quotidian life. EBTs have shown the potential to be viable contenders in the battle against obesity. With accumulating efficacy and safety data, these therapies will be an attractive therapeutic option in the coming years. Future research should focus on the tandem and sequential use of GI EBTs, along with obesity pharmacotherapies, to augment and enhance the durability of weight loss; hopefully, resulting in a lasting impact on obesity and its related co-morbidities.

\section{Conflicts of Interest}

Dr. Abu Dayyeh is a consultant for, and he has received a grant from Apollo Endosurgery. He is a consultant for Metamodix and Boston Scientific. He has received grant support from Aspire Bariatric and research support from GI Dynamics.

\section{REFERENCES}

1. Flegal KM, Carroll MD, Ogden CL, Curtin LR. Prevalence and trends in obesity among US adults, 1999-2008. JAMA 2010;303:235-241.

2. Ng M, Fleming T, Robinson M, et al. Global, regional, and national prevalence of overweight and obesity in children and adults during 1980-2013: a systematic analysis for the global burden of disease study 2013. Lancet 2014;384:766-781.

3. Adams KF, Schatzkin A, Harris TB, et al. Overweight, obesity, and mortality in a large prospective cohort of persons 50 to 71 years old. N Engl J Med 2006;355:763-778. 
4. Bellentani S, Marino M. Epidemiology and natural history of non-alcoholic fatty liver disease (NAFLD). Ann Hepatol 2009;8 Suppl 1:S4-S8.

5. Adams LA, Lymp JF, St Sauver J, et al. The natural history of nonalcoholic fatty liver disease: a population-based cohort study. Gastroenterology 2005;129:113-121.

6. Yanovski SZ, Yanovski JA. Long-term drug treatment for obesity: a systematic and clinical review. JAMA 2014;311:74-86.

7. Buchwald H, Estok R, Fahrbach K, et al. Weight and type 2 diabetes after bariatric surgery: systematic review and meta-analysis. Am J Med 2009;122:248-256.e5.

8. Schauer PR, Kashyap SR, Wolski K, et al. Bariatric surgery versus intensive medical therapy in obese patients with diabetes. N Engl J Med 2012;366:1567-1576

9. Finkelstein EA, Trogdon JG, Cohen JW, Dietz W. Annual medical spending attributable to obesity: payer-and service-specific estimates. Health Aff (Millwood) 2009;28:w822-w831.

10. Frühbeck G, Diez Caballero A, Gil MJ. Fundus functionality and ghrelin concentrations after bariatric surgery. N Engl J Med 2004;350:308-309.

11. Phillips RJ, Powley TL. Gastric volume rather than nutrient content inhibits food intake. Am J Physiol 1996;271(3 Pt 2):R766-R769.

12. Wahlen $\mathrm{CH}$, Bastens $\mathrm{B}$, Herve J, et al. The bioenterics intragastric balloon (BIB): How to use it. Obes Surg 2001;11:524-527.

13. ASGE Bariatric Endoscopy Task Force and ASGE Technology Committee, Abu Dayyeh BK, Kumar N, et al. ASGE bariatric endoscopy task force systematic review and meta-analysis assessing the ASGE PIVI thresholds for adopting endoscopic bariatric therapies. Gastrointest Endosc 2015;82:425-438.e5.

14. Abu Dayyeh BK, Eaton LL, Woodman G. A randomized, multi-center study to evaluate the safety and effectiveness of an intragastric balloon as an adjunct to a behavioral modification program, in comparison with a behavioral modification program alone in the weight management of obese subjects. Gastrointest Endosc 2015;81(5 Suppl):AB147.

15. FDA. ORBERA ${ }^{\mathrm{max}}$ Intragastric balloon system-P140008 [Internet]. Silver Spring: U.S. Food and Drug Administration; c2015 [updated 2015 Aug 5; cited 2015 Dec 7]. Available from: http://www.fda.gov/medicaldevices/ productsandmedicalprocedures/deviceapprovalsandclearances/recently-approveddevices/ucm457416.htm.

16. Crea N, Pata G, Della Casa D, et al. Improvement of metabolic syndrome following intragastric balloon: 1 year follow-up analysis. Obes Surg 2009;19:1084-1088.

17. Fuller NR, Pearson S, Lau NS, et al. An intragastric balloon in the treatment of obese individuals with metabolic syndrome: a randomized controlled study. Obesity (Silver Spring) 2013;21:1561-1570.

18. Lee YM, Low HC, Lim LG, et al. Intragastric balloon significantly improves nonalcoholic fatty liver disease activity score in obese patients with nonalcoholic steatohepatitis: a pilot study. Gastrointest Endosc 2012;76:756-760

19. Mui WL, Ng EK, Tsung BY, Lam CH, Yung MY. Impact on obesity-related illnesses and quality of life following intragastric balloon. Obes Surg 2010;20:1128-1132.

20. Kotzampassi K, Grosomanidis V, Papakostas P, Penna S, Eleftheriadis E. 500 intragastric balloons: what happens 5 years thereafter? Obes Surg 2012;22:896-903.

21. Gómez V, Woodman G, Abu Dayyeh BK. Delayed gastric emptying as a proposed mechanism of action during intragastric balloon therapy: Results of a prospective study. Obesity (Silver Spring) 2016;24:1849-1853.

22. Tai CM, Lin HY, Yen YC, et al. Effectiveness of intragastric balloon treatment for obese patients: one-year follow-up after balloon removal. Obes Surg 2013;23:2068-2074.

23. Dumonceau JM, François E, Hittelet A, Mehdi AI, Barea M, Deviere J. Single vs repeated treatment with the intragastric balloon: a 5-year weight loss study. Obes Surg 2010;20:692-697.

24. Genco A, Cipriano M, Bacci V, et al. Intragastric balloon followed by diet vs intragastric balloon followed by another balloon: a prospective study on 100 patients. Obes Surg 2010;20:1496-1500.
25. Genco A, Maselli R, Frangella F, et al. Effect of consecutive intragastric balloon $\left(\mathrm{BIB}^{\circ}\right)$ plus diet versus single $\mathrm{BIB}^{\circ}$ plus diet on eating disorders not otherwise specified (EDNOS) in obese patients. Obes Surg 2013;23:2075-2079.

26. Lopez-Nava G, Rubio MA, Prados S, et al. BioEnterics intragastric balloon $\left(\mathrm{BIB}^{\circ}\right)$. Single ambulatory center Spanish experience with 714 consecutive patients treated with one or two consecutive balloons. Obes Surg 2011;21:5-9.

27. FDA. ReShape integrated dual balloon system-P140012 [Internet]. Silver Spring: U.S. Food and Drug Administration; c2015 [updated 2015 Jul 28; cited 2015 Dec 7]. Available from: http://www.fda.gov/medicaldevices/ productsandmedicalprocedures/deviceapprovalsandclearances/recently-approveddevices/ucm 456293.htm.

28. Ponce J, Woodman G, Swain J, et al. The REDUCE pivotal trial: a prospective, randomized controlled pivotal trial of a dual intragastric balloon for the treatment of obesity. Surg Obes Relat Dis 2015;11:874-881.

29. Lopez-Nava G, Bautista-Castaño I, Jimenez-Baños A, Fernandez-Corbelle JP. Dual intragastric balloon: single ambulatory center Spanish experience with 60 patients in endoscopic weight loss management. Obes Surg 2015;25:2263-2267.

30. Ponce J, Quebbemann BB, Patterson EJ. Prospective, randomized, multicenter study evaluating safety and efficacy of intragastric dual-balloon in obesity. Surg Obes Relat Dis 2013;9:290-295.

31. Brooks J, Srivastava ED, Mathus-Vliegen EM. One-year adjustable intragastric balloons: results in 73 consecutive patients in the U.K. Obes Surg 2014;24:813-819.

32. Genco A, Dellepiane D, Baglio G, et al. Adjustable intragastric balloon vs non-adjustable intragastric balloon: case-control study on complications, tolerance, and efficacy. Obes Surg 2013;23:953-958.

33. FDA. Obalon balloon system-P160001 [Internet]. Silver Spring: U.S. Food and Drug Administration; c2016 [updated 2016 Sep 8; cited 2016 Dec 11]. Available from: http://www.fda.gov/medicaldevices/productsandmedicalprocedures/deviceapprovalsandclearances/recently-approveddevices/ucm520741.htm.

34. Sullivan S, Swain JM, Woodman G, et al. The obalon swallowable 6-month balloon system is more effective than moderate intensity lifestyle therapy alone: results from a 6- month randomized sham controlled trial. Gastroenterology 2016;150(4 Suppl 1):S1267.

35. Machytka E, Gaur S, Chuttani R, et al. Elipse, the first procedureless gastric balloon for weight loss: a prospective, observational, open-label, multicenter study. Endoscopy 2016 Dec 12 [Epub]. http://dx.doi. org/10.1055/s-0042-119296.

36. Marinos G, Eliades C, Raman Muthusamy V, Greenway F. Weight loss and improved quality of life with a nonsurgical endoscopic treatment for obesity: clinical results from a 3- and 6-month study. Surg Obes Relat Dis 2014;10:929-934.

37. Myall P. New endoscopic stent can lead to $100 \%$ EWL [Internet]. London: Bariatric News; c2012 [updated 2012 Jun 5; cited 2015 Dec 7]. Available from: http://www.bariatricnews.net/?q=node/102.

38. Abu Dayyeh BK, Rajan E, Gostout CJ. Endoscopic sleeve gastroplasty: a potential endoscopic alternative to surgical sleeve gastrectomy for treatment of obesity. Gastrointest Endosc 2013;78:530-535.

39. Abu Dayyeh BK, Acosta A, Camilleri M, et al. Endoscopic sleeve gastroplasty alters gastric physiology and induces loss of body weight in obese individuals. Clin Gastroenterol Hepatol 2017;15:37-43.e1.

40. Sharaiha RZ, Kedia P, Kumta N, et al. Initial experience with endoscopic sleeve gastroplasty: technical success and reproducibility in the bariatric population. Endoscopy 2015;47:164-166.

41. Lopez-Nava G, Galvao M, Bautista-Castaño I, Fernandez-Corbelle JP, Trell M. Endoscopic sleeve gastroplasty with 1-year follow-up: factors predictive of success. Endosc Int Open 2016;4:E222-E227.

42. Lopez-Nava G, Galvão MP, Bautista-Castaño I, Jimenez-Baños A, Fernandez-Corbelle JP. Endoscopic sleeve gastroplasty: how I do it? Obes Surg 2015;25:1534-1538.

43. Kumar N, Lopez-Nava G, Sahdala HNP, et al. Endoscopic sleeve gas- 
troplasty: multicenter weight loss results. Gastroenterology 2015;148(4 Suppl 1):S-179.

44. Lopez-Nava G, Sharaiha RZ, Neto MG, et al. Endoscopic sleeve gastroplasty for obesity: a multicenter study of 242 patients with 18 months follow-up. Gastroenterology 2016;150(4 Suppl 1):S26.

45. Espinós JC, Turró R, Mata A, et al. Early experience with the Incisionless Operating Platform ${ }^{\text {mi }}$ (IOP) for the treatment of obesity : the primary obesity surgery endolumenal (POSE) procedure. Obes Surg 2013;23:1375-1383.

46. López-Nava G, Bautista-Castaño I, Jimenez A, de Grado T, Fernandez-Corbelle JP. The primary obesity surgery endolumenal (POSE) procedure: one-year patient weight loss and safety outcomes. Surg Obes Relat Dis 2015;11:861-865.

47. Miller K, Turró R, Greve JW, Bakker CM, Buchwald JN, Espinós JC. MILEPOST multicenter randomized controlled trial: 12-month weight loss and satiety outcomes after pose ${ }^{\mathrm{SM}}$ vs. medical therapy. Obes Surg 2017;27:310-322.

48. Sullivan S, Swain JM, Woodman G, et al. 12 Month randomized sham controlled trial evaluating the safety and efficacy of targeted use of endoscopic suture anchors for primary obesity: the ESSENTIAL study. Gastroenterology 2016;150(4 Suppl 1):S25-S26.

49. Abu Dayyeh B, Rajan E, Gostout hJ. Gastric endoscopic remodeling techniques. Tech Gastrointest Endosc 2016 Dec 6 [Epub]. http://dx.doi. org/10.1016/j.tgie.2016.12.004

50. Huberty V, Ibrahim M, Hiernaux M, Chau A, Dugardeyn S, Deviere J. Safety and feasibility of an endoluminal-suturing device for endoscopic gastric reduction (with video). Gastrointest Endosc 2016 Aug 22 [Epub]. http://dx.doi.org/10.1016/j.gie.2016.08.007.

51. Thompson CC, Abu Dayyeh BK, Kushner R, et al. Percutaneous gastrostomy device for the treatment of class II and class III obesity: results of a randomized controlled trial. Am J Gastroenterol 2016 Dec 6 [Epub]. http://dx.doi.org/10.1038/ajg.2016.500.

52. Rubino F, Forgione A, Cummings DE, et al. The mechanism of diabetes control after gastrointestinal bypass surgery reveals a role of the proximal small intestine in the pathophysiology of type 2 diabetes. Ann Surg 2006;244:741-749.

53. Kaplan LM, Buse JB, Mullin C, et al. EndoBarrier therapy is associated with glycemic improvement, weight loss and safety issues in patients with obesity and type 2 diabetes on oral antihyperglycemic agents. Proceedings of the 76th scientific sessions; 2016 Jun 10-14; New Orleans, Louisiana, USA. Virginia: American diabetes association; 2016.

54. Rajagopalan H, Cherrington AD, Thompson CC, et al. Endoscopic duodenal mucosal resurfacing for the treatment of type 2 diabetes: 6-month interim analysis from the first-in-human proof-of-concept study. Diabetes Care 2016;39:2254-2261 